\title{
ANALISIS TINGKAT KESULITAN SISWA DALAM KEMAMPUAN MENYELESAIKAN MASALAH MATEMATIKA MATERI PERSAMAAN KUADRAT
}

\author{
Lala Intan Komalasari \\ STKIP Al Amin Dompu \\ * Corresponding Author. Email: lalaintankomalasari@gmail.com \\ Received: 05 Maret 2020; Revised: 24 Maret 2020; Accepted: 30 Maret 2020
}

\begin{abstract}
ABSTRAK
Penelitian ini bertujuan untuk menganalisis kesulitan - kesulitan siswa dalam menyelesaikan masalah matematika pada materi Persamaan Kuadrat Dan Fungsi Kuadrat, Teorema Faktor Dan Teorema Sisa Metode yang digunakan adalah menggunakan tes dan wawancara. Tes dilakukan kepada siswa sedangkan wawacara dilakukan kepada guru dan siswa. Sekolah yang merupakan tempat penelitian adalah SMA Advent Purwodadi sekolah ini adalah merupakan sekolah satu atap (SATAP) yang terdiri dari 300 siswa dari berbagai daerah Hasil wawancara guru menyatakan bahwa guru tidak terlalu mengalami kesulitan dalam mengajar materi Persamaan Kuadrat Dan Fungsi Kuadrat, Teorema Faktor Dan Teorema Sisa guru akan mengalami kesulitan apabila sudah masuk pada bentuk akar, sedangkan kesalahan yang dilakukan siswa bervariasi yaitu kesalahan fakta, kesalahan konsep, kesalahan prinsip dan kesalahan operasi. Solusi yang di tawarkan adalah pembelajaran dengan memberikan soal open- ended pada materi persamaan kuadrat dan untuk menentukan grafik fungsi kuadrat yaitu dengan mengkontruksi prinsip.

Kata Kunci. Penyelesaian Masalah Matematika, Persamaan Kuadrat
\end{abstract}

ABSTRACT
This study aims to analyze the difficulties of students in solving mathematical problems in the material Quadratic Equations and Quadratic Functions, Factor Theorem and Time Theorem The method used is to use tests and interviews. Tests are conducted on students while interviews are conducted on teachers and students. The school which is a place of research is Adventist Purwodadi High School. This school is a one-roof school (SATAP) consisting of 300 students from various regions. The teacher's interview results state that the teacher has no difficulty in teaching the material Quadratic Equations and Quadratic Functions, Theorem Factors and Theorems The rest of the teachers will experience difficulties if they have entered the root form, while the mistakes made by students vary, namely fact errors, concept errors, principle errors and operating errors. The solution offered is learning by giving open-ended questions to the material in quadratic equations and to determine the graph of quadratic functions, namely by constructing the principle.

Keywords. Mathematical Problem Solving, Quadratic Equations

How to Cite: Komalasari, L, I. (2020). Analisis Tingkat Kesulitan Siswa dlama Kemampuan Menyelesaikan Masalah Matematika Materi Persamaan Kuadrat. Histogram: Jurnal Pendidikan Matematika, 4(1), 139 - 150, doi: http://dx.doi.org/10.31100/histogram.v4i1.566

Permalink/DOI: http://dx.doi.org/10.31100/histogram.v4i1.566

\section{PENDAHULUAN}

Matematika perlu diberikan kepada semua siswa sejak dini untuk membekali siswa dengan kemampuan berpikir logis, analitis, sistematis, kritis, dan kreatif serta dapat memiliki kemampuan memperoleh, mengelola, dan memanfaatkan informasi untuk bertahan hidup pada keadaan yang selalu berubah, tidak pasti dan kompetitif (Depdiknas, 2006; Komalasari, L, 2019). 


\section{Histogram: Jurnal Pendidikan Matematika, 4 (1), 2020 - 140 Lala Intan Komalasari}

Tujuan, materi, proses, dan penilaian pembelajaran matematika dikelas akan selalu menyesuaikan dengan tuntutan perubahan zaman. Dengan demikian metode, model, pendekatan, dan strategi pembelajaran matematika yang digunakan guru dikelas akan ikut menentukan keberhasilan pencapaian tujuan pembelajaran matematika (Widiantari, I, K, M, Suarjana, \& Kusmariyatni, 2016)

Tujuan utama pembelajaran matematika di Sekolah Menengah Atas sebagaimana dikemukakan (Soedjadi, 2000) adalah (1) melatih cara berfikir dan bernalar dalam menarik kesimpulan; (2) mengembangkan aktivitas kreatif yang melibatkan imajinasi, intuisi dan penemuan dengan mengembangkan pemikiran divergen, orisinil, rasa ingin tahu, membuat prediksi serta mencoba-coba, (3) mengembangkan kemampuan memecahkan masalah dan (4) mengembangkan kemampuan menyampaikan informasi atau mengkomunikasikan gagasan. Hal tersebut sejalan dengan pendapat Musser dan Burger (Fadillah \& Surya, 2017; Komalasari, L, 2017) bahwa tujuan mempelajari matematika adalah sebagai alat bantu pemecahan masalah yang meliputi empat tahap, yaitu mengerti permasalahan, memikirkan permasalahan, menyelesaikan permasalahan dan memeriksa kembali cara yang digunakan dalam memecahkan masalah.

Tercapai atau tidaknya tujuan pendidikan dan pembelajaran matematika salah satunya dapat dinilai dari keberhasilan siswa dalam memahami matematika dan memanfaatkan pemahaman ini untuk menyelesaikan persoalan-persoalan matematika maupun ilmu-ilmu yang lain. Matematika menekankan pada pemecahan suatu masalah, masalah dalam matematika biasanya disajikan dalam bentuk soal matematika (Dwinata, 2019; Fadillah \& Surya, 2017; Indah, Y, Rohaendi, \& Rahmah, M, 2018). Suatu pertanyaan akan merupakan suatu masalah hanya jika seseorang tidak mempunyai aturan/hukum tertentu yang segera dapat dipergunakan untuk menemukan jawaban pertanyaan tersebut. Soal matematika diberikan kepada siswa sebagai alat evaluasi untuk mengukur kemampuan yang dimiliki siswa setelah menerima suatu materi. Hasil evaluasi ini dapat menunjukkan sejauh mana keberhasilan proses belajar mengajar dan letak kesalahan siswa (Fadillah \& Surya, 2017). Untuk meningkatkan hasil belajar matematika maka sumber kesalahan yang dilakukan siswa harus dapat segera diatasi. Siswa akan selalu mengalami kesulitan jika kesalahan sebelumnya tidak diperbaiki terutama soal yang memiliki karakteristik yang sama. Sehingga dengan menganalisis kesalahan siswa, guru dapat mengetahui hasil belajar siswa yang nantinya dapat digunakan untuk 


\section{Histogram: Jurnal Pendidikan Matematika, 4 (1), 2020 - 141 Lala Intan Komalasari}

memperbaiki proses belajar mengajar berikutnya (Indah, et.al, 2018). Namun umumnya siswa kurang memahami dan menguasai hal tersebut yang berakibat timbulnya kesalahan siswa dalam menyelesaikan soal-soal matematika. Pada dasarnya kesalahan siswa dalam menyelesaikan soal matematika antara lain disebabkan kurangnya penguasaan konsep matematika (Ferdianto \& Yesino, 2019; Juliant \& Noviartati, 2016). Kesalahan siswa yang lain dalam menyelesaikan soal matematika yaitu kurangnya ketelitian dalam menghitung. Siswa seringkali salah dalam menghitung suatu bentuk perkalian, pembagian, penjumlahan dan pengurangan (Lipianto \& Budiarto, Mega, 2013; Pramudya, S \& Sulaiman, 2019).

Guna mengatasi kesalahan yang dihadapi siswa, masalah itu perlu ditemukan dan dipastikan sumbernya, menanganinya, dengan harapan memecahkan masalahnya. Berbagai upaya telah dilakukan oleh guru guna mengatasi masalah kesulitan belajar khususnya dalam menyelesaikan soal-soal matematika (Febriana, 2018; Pramudya, S \& Sulaiman, 2019). Usaha-usaha yang telah dilakukan guru tampaknya belum membuahkan hasil yang optimal dalam meningkatkan kemampuan menyelesaikan soal-soal matematika. Kesulitan siswa pada umumnya disebabkan karena kesalahan menggunakan konsep, prinsip dankesulitan dalam memaham soal. Berdasarkan informasi itulah melahirkan banyak cara dalam pembelajaran yang di gunakan untuk mengurangi kesulitan belajar yang dialami siswa (Lipianto \& Budiarto, Mega, 2013).

Dari hasil penelitian yang dilakukan, menunjukkan bahwa siswa masih dalam mengerjakan soal persamaan kuadrat dan fungsi kuadrat, teorema faktor dan teorema sisa hal dapat di lihat dari lembar jawaban siswa.

Adapun yang menjadi tujuan dalam penulisan ini adalah :1) Untuk mengetahui kesulitan guru dalam mengajar materi persamaan kuadrat dan fungsi kuadrat, teorema faktor dan teorema sisa di SMA Advent Purwodadi; 2) Mengetahui kesulitan siswa dalam menyelesaikan soal matematika persamaan kuadrat dan fungsi kuadrat, teorema faktor dan teorema sisa di SMA Advent Purwodadi; 3) Mengetahui solusi untuk mengatasi kesulitan siswa dalam menyelesaikan soal yang persamaan kuadrat dan fungsi kuadrat, teorema faktor dan teorema sisa di SMA Advent Purwodadi.

\section{METODE PENELITIAN}

Penelitian ini termasuk ke dalam penelitian kualitatif. Subjek dalam penelitian ini adalah siswa di SMA Advent Purwodadi sedangkan fokus masalah dalam penelitian ini adalah hasil tes instrumen dan wawancara dengan guru matematika di SMA Advent 


\section{Histogram: Jurnal Pendidikan Matematika, 4 (1), 2020 - 142 Lala Intan Komalasari}

Purwodadi hasil pekerjaan siswa yang dianalisis adalah kesulitan siswa dalam menyelesaikan soal pada materi persamaan kuadrat dan fungsi kuadrat, teorema faktor dan teorema sisa yang berdasarkan hasil tes dan menganalisis kesulitan guru dalam menyampaikan materi berdasarkan hasil wawancara dengan guru. Uji Validitas dilakukan dengan mengguakan program SPSS for Windows versi 16.0. Dalam penelitian ini pengujian validitas hanya dilakukan terhadap 15 responden. Pengambilan keputusan berdasarkan pada nilai $\mathrm{r}_{\text {hitung }}($ Corrected Item-Total Correlation $)>\mathrm{r}_{\text {tabel }}$ sebesar 0,378 untuk df $=15-2=18 ; \alpha=0,05$ maka item/ pertanyaan tersebut valid dan sebaliknya. Uji reliabilitas dilakukan terhadap item pertanyaan yang dinyatakan valid. Suatu variabel akan dikatakn reliabel jika jawaban terhadap pertanyaan selalu konsisten. Analisis reliabel menggunakan metode Split Half . selanjutnya menghitung reliabilitasnya dengan menggunakan rumus Alpha Cronbach. Perhitungan dilakukan dengan menggunakan program SPSS. uji reliabilitas dilakukan terhadap item pertanyaan yang dinyatakan valid. Suatu variabel dikatakan reliabel atau handal jika jawaban terhadap pertanyaan selalu konsisten. Jadi hasil koefisien reliabilitas instrument tes materi persamaan kuadrat dan fungsi kuadrat adalah sebesar $r_{11}=0,929$, instrument wawancara adalah sebesar $r_{11}=$ 0,947, ternyata memiliki nilai "Alpha Cronbach" lebih besar dari 0,600, yang berarti kedua instrumen dinyatakan reliable atau memenuhi persyaratan.

\section{HASIL DAN PEMBAHASAN}

Berdasarkan hasil penelitian yang dilakukan di SMA Advent Purwodadi, di temukan bahwa sekolah tersebut merupakan sekolah satu atap (SATAP) yang terdiri dari SMP dan SMA yang terdiri dari 300 orang siswa SMP dan SMA, siswa yang ada di sekolah tersebut datang dari berbagai daerah ada yang dari Kalimantan, Sumatra, Jakarta, Sumbawa,Bengkulu hingga Papua. Siswa - siswa pendatang tersebut tinggal di asrama yang di sediakan oleh sekolah asrama di pisah untuk laki-laki dan perempuan. Berdasarkan hasil wawancara dengan guru matematika di SMA Advent Purwodadi guru saat mengajar materi persamaan kuadrat dan fungsi kuadrat, teorema faktor dan teorema sisa tidak terlalu banyak mengalami kesulitan kebetulan guru yang menjadi subjek adalah guru kelas IPA yang dimana siswanya memiliki kemampuan diatas siswa - siswa yang lain.

Dalam praktik, pembelajaran matematika biasanya dimulai dengan penjelasan konsep-konsep disertai dengan contoh-contoh, dilanjutkan dengan latihan soal-soal. Pendekatan pembelajaran ini didominasi oleh penyajian masalah matematika dalam bentuk tertutup yaitu permasalahan matematika yang dirumuskan sedemikan rupa, 


\section{Histogram: Jurnal Pendidikan Matematika, 4 (1), 2020 - 143 Lala Intan Komalasari}

sehingga hanya memiliki satu jawaban yang benar dengan satu pemecahanannya (Dwinata, 2019; Pomalo, Kaluku, \& Usman, 2015; Tokip, 2016). Di samping itu, permasalahan tertutup ini biasanya disajikan secara terstruktur dan eksplisit, mulai dengan yang diketahui, apa yang ditanyakan, dan konsep apa yang digunakan untuk memecahkan masalah itu. Ide-ide, konsep-konsep dan pola hubungan matematika serta strategi, teknik dan algoritma pemecahan masalah diberikan secara eksplisit, sehingga siswa dengan mudah dapat menebak solusinya. Pendekatan pembelajaran seperti ini cenderung hanya melatih keterampilan dasar matematika secara terbatas dan terisolasi (Aditya, 2015; Ulifa, Siti, 2014).

Pada tulisan ini peneliti menemukan kesulitan siswa dalam menyelesaikan soal persamaan kuadrat dan fungsi kuadrat, teorema faktor dan teorema sisa, alasan yang bervariasi yang ditemukan dari siswa karena tidak hanya pada hasil tes yang dilakukan tetapi juga hasil wawancara singkat dengan beberapa siswa, alasan yang dikemukakan adalah kurang memahami soal, serta waktu yang disediakan sangat sedikit sehingga ada soal yang tidak sempat diselesaikan oleh siswa.

Sebelum memberikan tes kepada siswa, peneliti terlebih dahulu menanyakan apakah siswa mampu menyelesaikan soal yang akan di berikan, Berdasarkan hasil tes yang di berikan pada siswa banyak di temukan keslahan siswa dalam menyelesaikan soal Persamaan Kuadrat Dan Fungsi Kuadrat, Teorema Faktor Dan Teorema Sisa kesalahan tersebut terdiri dari kesalahan fakta, kesalahan prinsip, kesalahan konsep dan kesalahan operasi, untuk lebih jelasnya mengenai jenis kesalahan yang dialami siswa dapat di lihat pada tabel di bawah ini.

Tabel 1. Jumlah Kesalahan Siswa

\begin{tabular}{|c|c|c|c|c|c|}
\hline $\mathbf{N}$ & Soal & Kesalah: & an siswa & benar & lah \\
\hline 1 & $\begin{array}{l}\text { Akar - akar } \\
\text { persamaan } \\
\text { kuadrat } 3 x^{2}+ \\
2 x-5=0 \\
\text { adalah } x^{1} \text { dan } \\
x^{2} \text { hitunglah } \\
\text { nilai dari } \frac{1}{x^{1}}+ \\
\frac{1}{x^{2}}\end{array}$ & $\begin{array}{l}\text { (1) } 3 u^{2}+2 u-5=0 \\
\quad(3 u+5)(v-1) \\
3 u+5=0 \quad \mid u=1 \quad \rightarrow \\
3 u=5 \\
u=\frac{5}{3}\end{array}$ & $\begin{aligned} \frac{1}{v_{1}}+\frac{1}{v_{2}} & =\frac{1}{\frac{5}{3}}+\frac{1}{1} \\
& =\frac{1}{\frac{5}{3}}+\frac{\frac{3}{5}}{\frac{5}{3}} \\
& =\frac{5+3}{5}=\frac{8}{5}\end{aligned}$ & 10 & 10 \\
\hline
\end{tabular}


Histogram: Jurnal Pendidikan Matematika, 4 (1), 2020 - 144

Lala Intan Komalasari

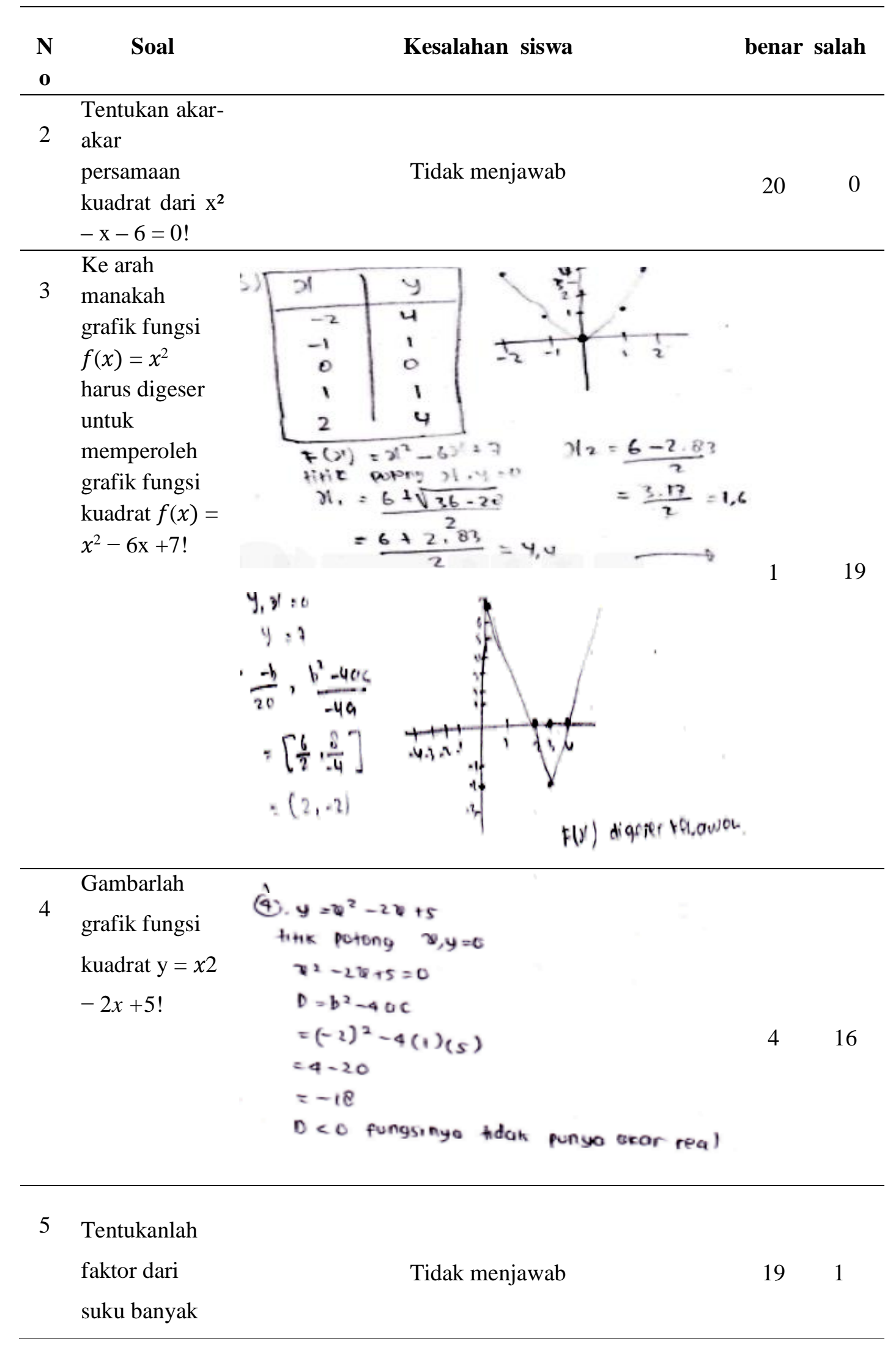


Histogram: Jurnal Pendidikan Matematika, 4 (1), 2020 - 145

Lala Intan Komalasari

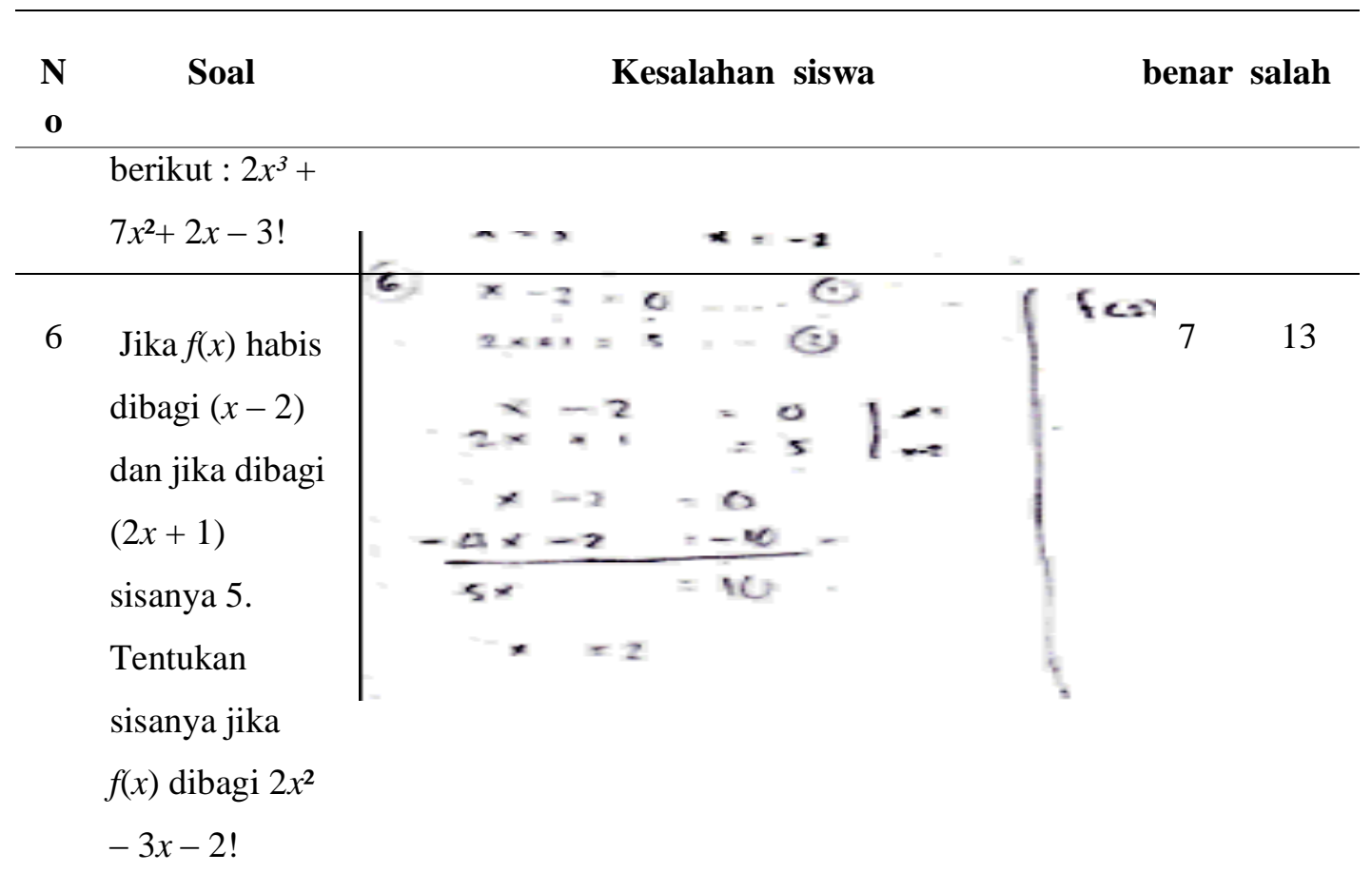

(Sumber: Data Primer, Tahun: 2019)

Tabel 2. Jumlah Siswa yang Melakukan Kesalahan dan Jenis Kesalahan Siswa

Jenis
kesalahan
siswa $\quad$ Jumlah siswa yang melakukan kesalahan

Fakta

Tidak ada

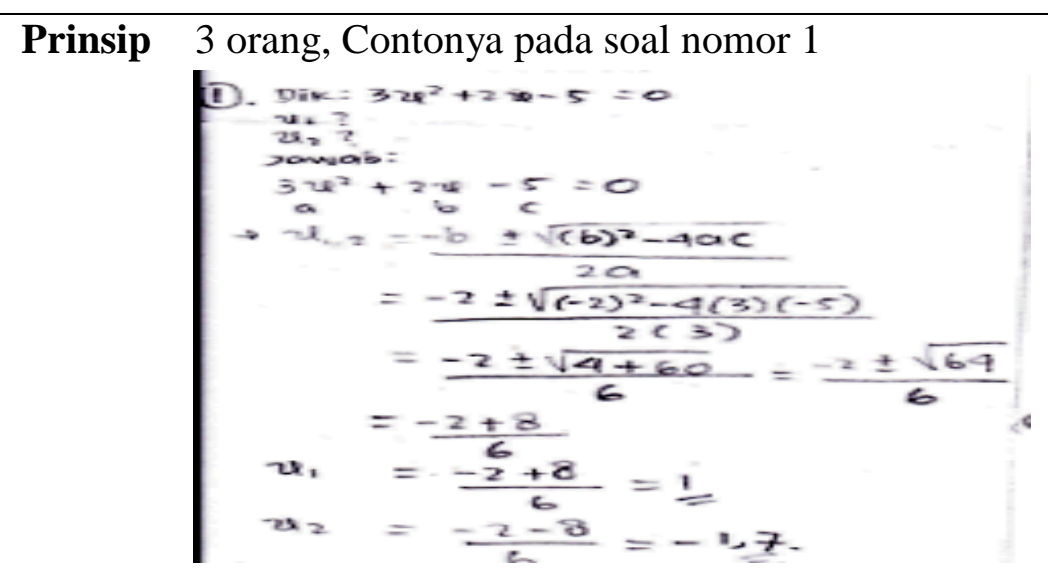


Histogram: Jurnal Pendidikan Matematika, 4 (1), 2020 - 146
Lala Intan Komalasari

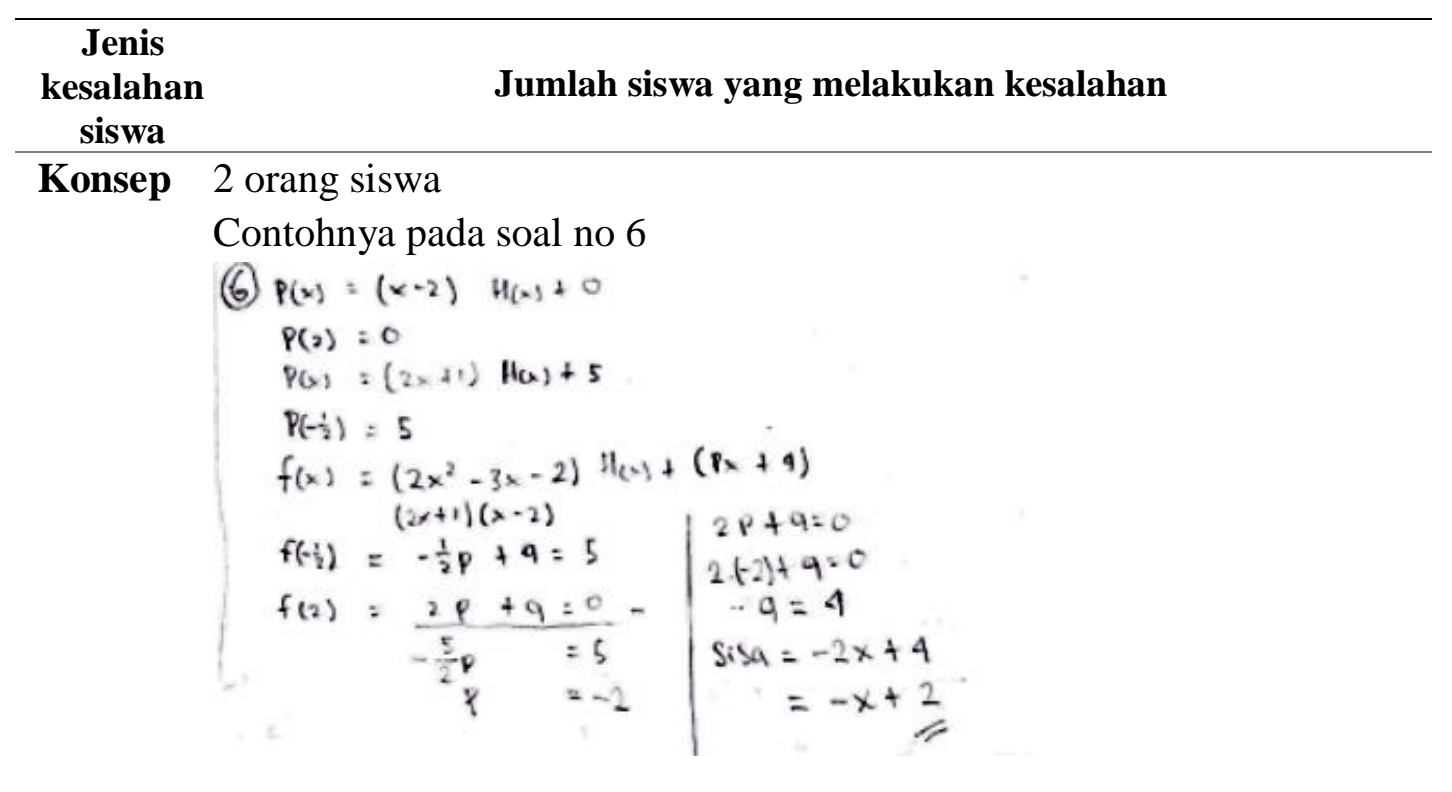

\section{Operasi 5 orang siswa contohnya pada soal 1}

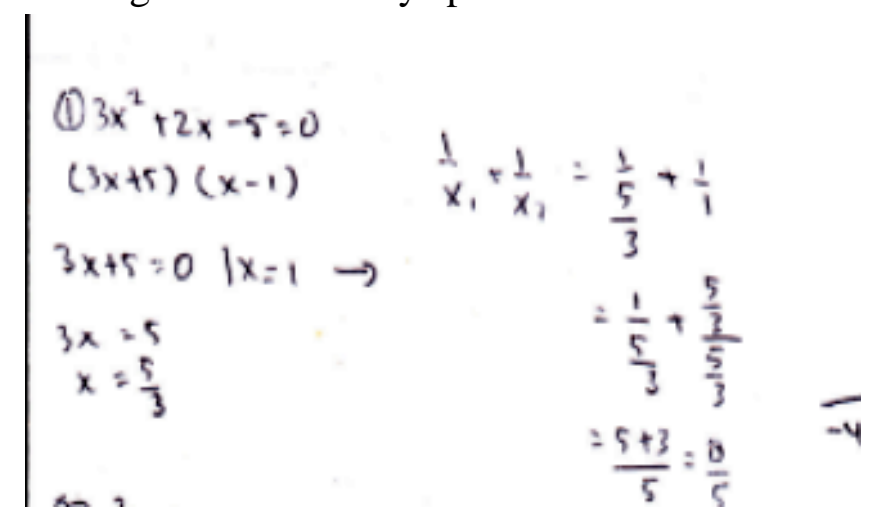

(Sumber: Data Primer, Tahun: 2019)

Berdasarkan hasil tes yang dilakukan kepada siswa di SMA Advent Purwodadi kesulitan banyak di temukan pertama, pada soal persamaan kuadrat peneliti menawarkan pembelajaran dengan pemecahan masalah menggunakan persoalan open - ended. Model ini berpotensi mengembangkan meningkatkan penguasaan konsep, keterampilan berpikir divergen, dan pengembangan pemecahan masalah (Tokip, 2016). Adapun langkah langkah pemecahan masalah yaitu dengan memahami masalah, merencanakan, melaksanakan dan memeriksa kembali Misalnya: Akar - akar persamaan kuadrat $3 x^{2}+$ $2 \mathrm{x}-5=0$ adalah $x_{1}$ dan $x_{2}$ hitunglah nilai dari $\frac{1}{x_{1}}+\frac{1}{x_{2}}$

Pada tahap memahami siswa diminta untuk memahami apa yang diketahui dari masalah. Pada soal di atas siswa diminta memahami bahwa persamaan yang diketahui 


\section{Histogram: Jurnal Pendidikan Matematika, 4 (1), 2020 - 147 Lala Intan Komalasari}

memiliki akar-akar $\mathrm{x}_{1}$ dan $\mathrm{x}_{2}$, sedangkan yang ditanyakan nilai dari $\frac{1}{\mathrm{x}_{1}}+\frac{1}{\mathrm{x}_{2}}$. Pada tahap merencanakan siswa diminta membuat perencanaan penyelesaian dari apa yang diketahui dan ditanyakan. Misalkan dengan mencari akar-akar persamaan kemudian menghitung nilai yang ditanyakan. Setelah itu siswa diminta siswa melaksnakan rencananya kemudian pada tahap terakhir siswa mngecek kembali apa yang sudah dilaksanakan, apakah jawabannya sudah sesuai dengan permintaan soal.

Kedua, pada materi pokok fungsi kuadrat meliputi : kesulitan memfaktorkan bentuk persamaan kuadrat untuk menentukan titik potong grafik dengan sumbu $\mathrm{x}$, menentukan titik-titik pada bidang kartesius, menggambar model grafik fungsi kuadrat.dari hasil penelitian yang dilakukan kesalahan di temukan adalah menggambar grafik fungsi kuadrat dan menentukan titik pada bidang kartesius. Penyebab kesulitan ini, karena siswa belum memahami pengetahuan prasyarat yang diperlukan misalnya untuk menguasai fungsi kuadrat harus menguasai persamaan kuadrat, penyederhanaan bentukbentuk aljabar, memfaktorkan bentuk aljabar (Komalasari, L, 2019). Alternatif cara mengatasi prinsip dalam materi pokok fungsi kuadrat adalah dengan mengkonstruksikan prinsip atau aturan yaitu dengan mengarahkan siswa untuk menggambarkan grafik dengan langkah -langkah yang pertama, dengan mengarahkan siswa untuk menentukan titik - titik terlebih dahulu yang akan di buat pada bidang cartesius, yang kedua siswa di arahkan untuk menentukan letak titik pada bidang cartesius kemudian di arahkan untuk menarik garis sesuai dengan titik yang telah di tentukan (Febriana, 2018; Pramudya, S \& Sulaiman, 2019). Selain itu juga bisa menggunakan langkah - langkah seperti di bawah ini. Misalnya pad soal no 3, Ke arah manakah grafik fungsi $f(x)=x^{2}$ harus digeser untuk memperoleh grafik fungsi kuadrat $f(x)=x^{2}-6 x+7$ !

Adapun langkah penyelesaiannya adalah sebagai berikut: (1) Mencari posisi fungsi kuadrat $\mathrm{f}(\mathrm{x})=\mathrm{x}^{2}$; (2) a $>0$ sehingga parabola terbuka keatas; (3) $\mathrm{b}=0$ sehingga titik balik parabola berada pada sumbu y; (3) $\mathrm{c}=0$ sehingga grafik parabola melalui titik $(0,0)$. Gambar grafiknya adalah sebagai berikut: 


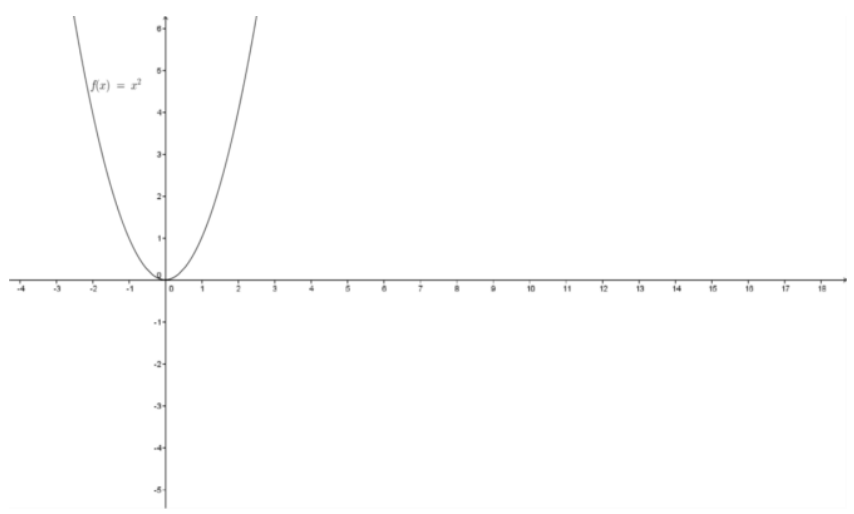

Gambar 1. Grafik fungsi kuadrat

Mencari posisi, fungsi kuadrat $\mathrm{f}(\mathrm{x})=x^{2}-6 x+7$ memiliki nilai : (1) a $>0$ sehingga parabola terbuka keatas; (2) $b=-6$ maka $a-b=-6<0$ sehingga titik balik ada kanan sumbu y; (3) c $=7>0$ sehingga parabola memotong sumbu y di atas sumbu $\mathrm{x}$

Karena titik balik ada di kanan sumbu y, berarti grafik $\mathrm{f}(\mathrm{x})=x^{2}$ harus di geser ke arah kanan sumbu x. untuk lebih jelasnya kita dapat menentukan terlebih dahulu titik titik yang di butuhkan, yaitu : (1) sumbu simetri $=\mathrm{x}=\frac{-b}{2 a}=\frac{-(-6)}{2(1)}=3$; (2) nilai ekstrim $=\mathrm{y}=\mathrm{f}\left(\frac{-b}{2 a}\right)=\mathrm{f}(3)=3^{2}-6(3)=3^{2}-6(3)+7=-2 ;(3)$ titik balik $=(3,-2)$. Gambar grafiknya adalah sebagai berikut:

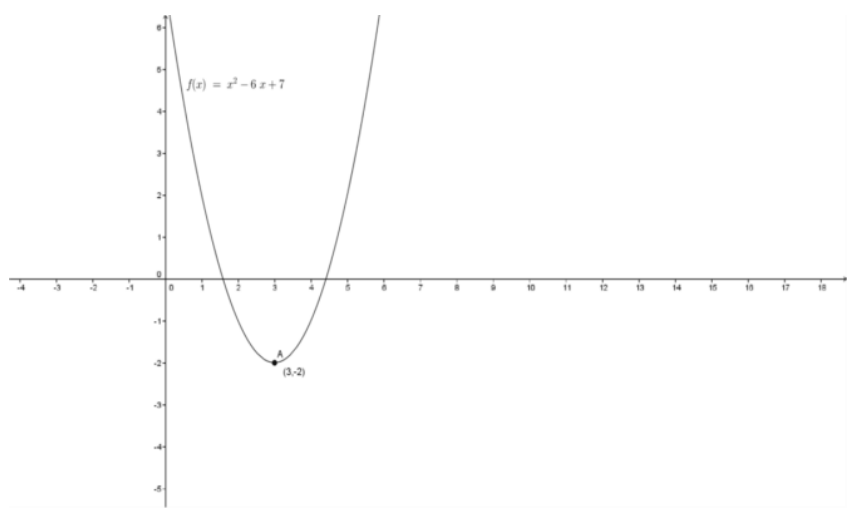

Gambar 2. Grafik fungsi kuadrat

Jadi grafik $f(x)=x^{2}$ melalui titik $(0,0)$ sedangkan grafik $f(x)=x^{2}-6 x+7$ melalui titik $(3,-2)$, maka kita dapat menggambar grafik fungsi kuadrat $f(x)=x^{2}-6 x+7$ dengan menggeser grafik fungsi kuadrat $f(x)=x^{2}$ kearah kanan sumbu $x$ sejauh 3 satuan dan kearah bawah sumbu y sejauh 2 satuan. 


\section{Histogram: Jurnal Pendidikan Matematika, 4 (1), 2020 - 149 Lala Intan Komalasari}

Ketiga, pada penyelesaian soal suku banyak peneliti menawarkan solusi yang sama dengan materi persamaan kuadrat dengan langkah - langkah yang sama dan langkah - langkahnya di sesuaikan dengan bentuk soal yang di berikan keapada siswa (Alona, 2019).

\section{KESIMPULAN DAN SARAN}

\section{A. Kesimpulan}

Berdasarkan hasil tes dan wawancara yang dilakukan terhadap guru dan serangkaian tes yang diberikan pada siswa peneliti menyimpulkan bahwa: (1) Guru tidak terlalu mengalami kesulitan dalam mengajar materi Persamaan Kuadrat Dan Fungsi Kuadrat, Teorema Faktor Dan Teorema Sisa guru akan mengalami kesulitan apabila sudah masuk pada bentuk akar, (2) Sedangkan kesalahan yang dilakukan siswa bervariasi yaitu kesalahan fakta, kesalahan konsep, kesalahan prinsip dan kesalahan operasi. (3) Solusi yang di tawarkan adalah pembelajaran dengan memberikan soal open - ended pada materi persamaan kuadrat dan untuk menentukan grafik fungsi kuadrat yaitu dengan mengkontruksi prinsip.

\section{B. Saran}

Penelitian ini jauh dari sempurna dan semoga penelitan ini bermanfaat bagi penelitian lainnya, selanjutnya diharapkan untuk menganalisis lebih banyak sumber maupun referensi yang berkaitan dengan sarana dan prasarana pendidikan maupun efektivitas serta proses pembelajaran sehingga menghasikan penelitian yang lebih baik lagi. Selanjutnya untuk peneliti lainya agar lebih mempersiapkan diri dalam proses penumpulan data dan disertakan pula dengan wawancara untuk memperkuat hasil penelitian.

\section{DAFTAR PUSTAKA}

Aditya, Y. (2015). Analisis Kesalahan Siswa SMP Kelas VII dalam Menyelesaikan Masalah Matematika Materi Segiempat ditinjau dari Gaya Belajar. Semarang: Skripsi Pendidikan Matematika Universitas Negeri Semarang.

Depdiknas. (2006). Kurikulum Tingkat Satuan Pendidikan, Standar Kompetensi Matematika SMP Dan MTs. Jakarta: Kemendiknas.

Dwinata, A. (2019). Analisis Kemampuan Pemecahan Masalah Menggunakan Pemodelan RASCH pada Materi Permutasi dan Kombinasi. In PRISMA, Prosiding Seminar Nasional Matematika (pp. 124-131). Semarang: Universitas Negeri Semarang.

Fadillah, N., \& Surya, E. (2017). Perbandingan Kemampuan Pemecahan Masalah Matematis Siswa menggunakan Model Elcity Activities dan Problem Based Learning di Kelas VIII SMP Negeri 38 Medan. Jurnal Inspiratif, 3(1), 1-9.

Febriana, E. (2018). Analisis Kemampuan Pemecahan Masalah Ditinjau Dari 


\section{Histogram: Jurnal Pendidikan Matematika, 4 (1), 2020 - 150 Lala Intan Komalasari}

Kepercayaan Diri Siswa Kelas IX Pada Materi Program Linear. Kediri.

Ferdianto, F., \& Yesino, L. (2019). Analisis Kesalahan Siswa dalam Menyelesaikan Soal Pada Materi SPLDV Ditinjau dari Indikator Kemampuan Matematis. Jurnal SJME, $3(1), 32-35$.

Indah, Y, W., Rohaendi, S., \& Rahmah, M, A. (2018). Penerapan model pembelajaran gallery walk untuk meningkatkan kemampuan pemahaman matematis dan dampaknya pada kepercayaan diri siswa SMA. BIORMATIKA : Jurnal Ilmiah FKIP Universitas Subang, 4(1).

Juliant, A., \& Noviartati, K. (2016). Analisis Kesalahan Siswa dalam Menyelesaikan Soal Pada Materi Pola Bilangan Ditinjau Dari Kemampuan Matematika Siswa. Jurnal Riset Pendidikan, 2(2), 111-118.

Komalasari, L, I. (2017). Analisis Tingkat Kesulitan Siswa dalam Menyelesaikan Masalah Matematika pada Materi Geometri dan Bilangan Bulat yang Berbentuk Soal Cerita. Al-Furqan, 6(1), 22-35.

Komalasari, L, I. (2019). Analisis Kemampuan Siswa Dan Guru SMK Dalam Menyelesaikan Masalah Matematika. Histogram: Jurnal Pendidikan Matematika, 3(2), 189-198.

Lipianto, D., \& Budiarto, Mega, T. (2013). Analisis Kesalahan Siswa dalam Menyelesaikan Soal yang berhubungan dengan Persegi dan Persegi Panjang berdasarkan Taksonomi Solo Plus pada Kelas VII. MathEdunesa, 2(1), 99-103.

Pomalo, A., Kaluku, A., \& Usman, K. (2015). Analisis Kesalahan Siswa pada dalam Menyelesaikan Soal-Soal Operasi Campuran Materi Operasi Hitung Bilangan Bulat. Gorontalo: Skripsi Pendidikan Matematika Universitas Negeri Gorontalo.

Pramudya, S, A., \& Sulaiman, H. (2019). Analisis Kebutuhan Game Edukasi Mahasiswa dalam Menyelesaikan Materi Prasyarat Persamaan Differensial. Euclid, 6(1), 74-83.

Soedjadi, R. (2000). Kiat pendidikan matematika di Indonesia: konstatasi keadaan masa kini menuju harapan masa depan. Jakarta: Direktorat Jenderal Pendidikan Tinggi, Departemen Pendidikan Nasional.

Tokip, R. (2016). Analisis Kesalahan Siswa dalam Menyelesaikan masalah Aljabar. Universitas Nusantara PGRI Kediri.

Ulifa, Siti, N. (2014). Hasil Analisis Kesalahan Siswa Dalam Menyelesaika soal Matematika Pada Materi Relasi. Jurnal Pendidikan Matematika STKIP PGRI Sidoarjo, 2(1), 123-133.

Widiantari, I, K, M, P., Suarjana, M., \& Kusmariyatni, N. (2016). Analisis Kemampuan Berpikir Kritis Siswa Kelas IV Dalam Pembelajaran Matematika. Journal PGSD Pendidikan Ganesha, 4(1), 1-11. 